\title{
The "Moving Heart Program": an intervention to improve physical activity among patients with coronary heart disease ${ }^{1}$
}

\author{
Roberta Cunha Matheus Rodrigues ${ }^{2}$ \\ Thaís Moreira São João ${ }^{3}$ \\ Maria Cecília Bueno Jayme Gallani² \\ Marilia Estevam Cornélio ${ }^{3}$ \\ Neusa Maria Costa Alexandre ${ }^{2}$
}

\begin{abstract}
Aim: this paper reports the results of a nursing-administered theory-based intervention, the "Moving Heart Program", based on the implementation intention theory and pointed at improving physical activity adherence among coronary heart disease outpatients in Brazil. Methods: this experimental study applied assessments at baseline, 1 and 2 months after baseline. The Consolidated Standards of Reporting Trials statement was followed. Participants were randomly assigned to intervention, comprising action and coping plans on how to deal with anticipated barriers $(n=69)$, or a standard-care control group $(n=67)$. Results: participants submitted to the intervention showed significant higher levels of physical activity 2 months after baseline and were significantly more active than the control group. Conclusions: the results indicate that the intervention is feasible for patients with coronary heart disease and can be a useful tool to facilitate intended lifestyle changes. This study brings relevant contributions to the Nursing field and other health-related areas, once the intervention presents low cost to health services and can be applied in cardiac rehabilitation programs, showing significant benefits to participants.

Descriptors: Nursing; Motor Activity; Behavior; Myocardial Ischemia; Planning Techniques.
\end{abstract}

\footnotetext{
${ }^{1}$ Supported by Fundação de Amparo à Pesquisa do Estado de São Paulo (FAPESP), process \#2007/57400-0.

2 PhD, Associate Professor, Faculdade de Enfermagem, Universidade Estadual de Campinas, Brazil.

${ }^{3} \mathrm{RN}, \mathrm{PhD}$.
} 


\title{
"Programa Coração em Movimento": intervenção para promover atividade física entre pacientes com doença arterial coronária
}

Objetivo: este estudo reporta os resultados de uma intervenção denominada "Programa Coração em Movimento", baseada nos pressupostos teóricos da "implementação da intenção", para incrementar o nível de atividade física entre pacientes coronariopatas, em seguimento ambulatorial, no Brasil. Métodos: neste estudo experimental foram avaliados os pacientes numa abordagem inicial, um e dois meses após. A declaração CONSORT foi seguida. Os participantes foram aleatoriamente alocados nos grupos intervenção (GI) e controle (GC). O GI $(n=69)$ foi submetido ao planejamento de ação e de enfrentamento de obstáculos e o GC $(n=67)$ recebeu tratamento de rotina. Resultados: os participantes submetidos à intervenção apresentaram níveis significativamente mais elevados de atividade física dois meses após a abordagem inicial e foram mais ativos do que aqueles no GC. Conclusões: os resultados indicam que a intervenção é possível ser aplicada em pacientes coronariopatas e pode ser uma ferramenta útil para facilitar mudanças no estilo de vida. Este estudo traz contribuições relevantes para a área de enfermagem e outras áreas afins, uma vez que essa intervenção apresenta baixo custo aos serviços de saúde e pode ser aplicada em programas de reabilitação cardíaca, com evidências de benefícios significativos aos participantes.

Descritores: Enfermagem; Atividade Motora; Comportamento; Isquemia Miocárdica; Técnicas de Planejamento.

\section{"Programa de Corazón en Movimiento": una intervención para mejorar la actividad física en pacientes con enfermedad coronaria}

\begin{abstract}
Objetivo: en este estudio, se presentan los resultados de una intervención de enfermería "El Programa Corazón en Movimiento", basada en las premisas teóricas del "implementation intention" para mejorar la actividad física entre pacientes con enfermedad coronaria en Brasil. Métodos: este estudio experimental aplicó las evaluaciones al inicio del estudio, 1 y 2 meses después. La declaración Consolidated Standards of Reporting Trials fue seguida. Los participantes fueron asignados al azar al Grupo Intervención, que comprende los planes de acción y de hacer frente a la manera de lidiar con los obstáculos $(n=69)$; o al Grupo Control $(n=67)$. Resultados: los participantes sometidos a la intervención mostraron niveles significativamente más altos de actividad física después de 2 meses y eran más activos que los del grupo control. Conclusión: la intervención es viable para pacientes con enfermedad coronaria y es una herramienta útil para facilitar los cambios de estilo de vida. Este estudio aporta contribuciones relevantes en el campo de enfermería y de otras áreas relacionadas a la salud, una vez que la intervención tiene costo bajo para los servicios de salud y se puede aplicar en los programas de rehabilitación cardíaca, y muestra beneficios significativos para los participantes.
\end{abstract}

Descriptores: Enfermería; Actividad Motora; Comportamiento; Enfermedad Coronaria; Técnicas de Planificación.

\section{Introduction}

Regular moderate-intensity physical activity (PA) has an important influence on health status and wellbeing(1). Aerobic PA also plays a crucial role in the prevention and rehabilitation of coronary heart disease (CHD) by providing the systemic benefits and reducing cardiovascular symptoms ${ }^{(2)}$. PA is therefore, an essential part of cardiac rehabilitation programs ${ }^{(2)}$.

Practice guidelines to increase adherence to the PA highlight the advantages of exercise and its benefits on health, and recommend the participation in at least 30 minutes of moderate-intensity PA, preferably all days of the week ${ }^{(1)}$. However, there is evidence of low adherence to PA in different socioeconomic and cultural contexts. According to the American Heart Association (AHA) Statistics 2010, the proportion of adults meeting the current recommendations for regular PA (performing at least 30 minutes of moderate PA 5 or more days per week, or 20 minutes of vigorous PA 3 or more days 
per week) has declined over time ${ }^{(3)}$. These findings suggest that effectively engaging CHD outpatients in any kind of PA represents a challenge to nursing and multidisciplinary team in cardiovascular rehabilitation.

Considering the low levels of PA among heart disease population ${ }^{(3)}$, worldwide recommendations point to the need of developing strategies focused on improving compliance to PA guidelines ${ }^{(1)}$. It is worthwhile to use interventions based on theories since theory has three distinct utilities with the purpose of developing means to change behavior: 1 ) to understand which theoretical constructs best explain or predict behavior, providing a focus to the intervention and allowing the efforts to be concentrated on changing those constructs; 2 ) to detect effective techniques for altering these constructs and offer direction as to 'how' behavior may be altered and 3 ) to permit evaluation of 'why' modification happened(4).

Recent studies have focused on a specific type of theory-based intervention to promote behavioral changes, based on the concept of implementation intentions, which refers to a post intentional process of self-regulating a behavior(5). Some authors have named it as Action and Coping Planning(6). This strategy comprises planning accomplishment of intentions through specification of when, where and how the actions to accomplish the desired behavior ${ }^{(5)}$ - individuals who fulfill these instructions are more favorable to initiate and maintain the behavior - setting the formulation of a specific plan seems to be a promising way to translate intention into action. Additionally, a meta-analysis indicated that action plans/implementation intentions had an overall effect size of 0.65 on goal attainment ${ }^{(7)}$.

Although several studies based on implementation intentions have demonstrated to be effective in promoting PA and others health-related behaviors, to our knowledge, none similar nursing-driven intervention is described in Brazil, among coronary heart disease outpatients attended by the Public Health System, characterized by their low income and education levels. The nursing staff in Brazil represents the most significant percentage of health professionals within the Public Health System with an impressive capacity to reach a massive proportion of the population. Therefore, nurses in this context can play a pivotal role in the development, implementation and evaluation of interventions aimed to change health-related behaviors, as well as increasing the level of PA in particular populations as patients with cardiovascular diseases. For nurses to use theory-based interventions it is important to understand what, where, when and how, to change a behavior, and to provide the key elements for the measurement of the effect of the intervention.

\section{Background}

The use of theory-based interventions aimed to change health-related behaviors is expected to achieve better results since they provide keys to design specific strategies for the main behavioral determinants ${ }^{(4)}$. Studies have shown the efficacy of interventions based on different theoretical backgrounds to encourage the adoption of healthy behaviors, including PA, and analysis of these studies indicate that the description of interventions is often not clear or sufficiently objective to be reproduced, while the interventions are not always successful( ${ }^{(8)}$. However, a study reported positive results with the use of strategies of action and coping planning aimed to optimize the compliance to PA among patients in a cardiac rehabilitation program ${ }^{(9)}$.

These strategies are based on the concepts of implementation intentions, described as a process serving to promote the achievement of the behavioral goal specified in the formation of the intention ${ }^{(5)}$. Intention is considered the main determinant of behavior and specifies a desired end point that may be a performance or an outcome. There is a gap, known worldwide, in the intention-behavior relationship ${ }^{(10)}$. The fragile intentionbehavior relationship is mostly due to people expressing good intentions, but failing to implement them ${ }^{(11)}$. So, implementation intentions can enhance the initiation of action, since they are secondary to intentions and act through the specification of when, where, and how the behavior will be performed(12).

While some studies have focused in understanding the effect of volitional strategies in behavior achievement(12-13), other sought to evaluate the effects of the association between volitional and motivational interventions $^{(14)}$. In a study developed in the UK, the motivational intervention did not affect the subsequent behavior, but the addition of volitional intervention (implementation intentions) produced a significant increase in behavior ${ }^{(14)}$. This indicates that motivational intervention may be more effective if associated with volitional intervention. In this context, relevant action plans specifying where and when to get started have been demonstrated to be useful to encourage action or to translate motivation into effective behavior(15).

Nevertheless, there is evidence that maintaining the behavior for an extended period of time during which all kinds of frustrations and obstacles may interfere 
with prolonged goal-directed action is a difficult task ${ }^{(16)}$. Dealing with difficulties during these later stages of goal pursuit requires a different type of plan that specifies in what way individuals will cope with threats to their goal - or Coping Plans(9). Recent study showed that self-regulatory skills that relate anticipating future obstacles and finding ways to deal with them are the most important in behavioral maintenance ${ }^{(17)}$.

Therefore, the nurse-driven intervention, named "Moving Heart Program", is based on the implementation of intentions and comprises two steps of planning, in order to plan, initiate and maintain the desired change despite the difficulties that may emerge.

\section{Objectives}

The aim of the study was to examine the effectiveness of the "Moving Heart Program", a behavioral intervention based on action planning combined with coping planning to increase PA among Brazilian patients with coronary heart disease (CHD).

\section{Methods}

An experimental study was conducted over a twomonth period (Figure 1). The CONSORT Statement was followed. Data were collected over a 13-month period between February 2008 and March 2009. The first measurement was taken at baseline (Time 0), the second measurement was taken one month after Time
0 (Time 1), and the third measurement was taken two months after Time 0 (Time 2). At Time 0, participants were randomly assigned to intervention (IG) or control group (CG). Fifteen days after baseline (15 th day) and fifteen days after Time 1 ( $45^{\text {th }}$ day), IG received phone reinforcement of the action and coping plans formulated previously.

Participants were recommended to engage in regular exercise, such as cycling or walking at least three times a week for a minimum of 30 minutes. Furthermore, they were advised to increase their everyday PA, for example, by using a bicycle instead of a car, or using the stairs instead of the elevator.

\section{Sample/Participants}

A random sample of participants was recruited from an outpatient clinic specialized in cardiology, at a university hospital in Campinas, a large urban center with one million inhabitants in the Southeastern of Brazil.

The sample size was estimated considering two independent samples based on the minimal expected difference between the averages of two groups (at least 1 -score point). Respecting power of .80 and $\alpha=.05$, a sample size of $n=43$ for each group was determined. Participants were recruited at the day of their regular consultation with the cardiologist. They were invited to participate in the research and their agreement was formalized by signing the consent term.
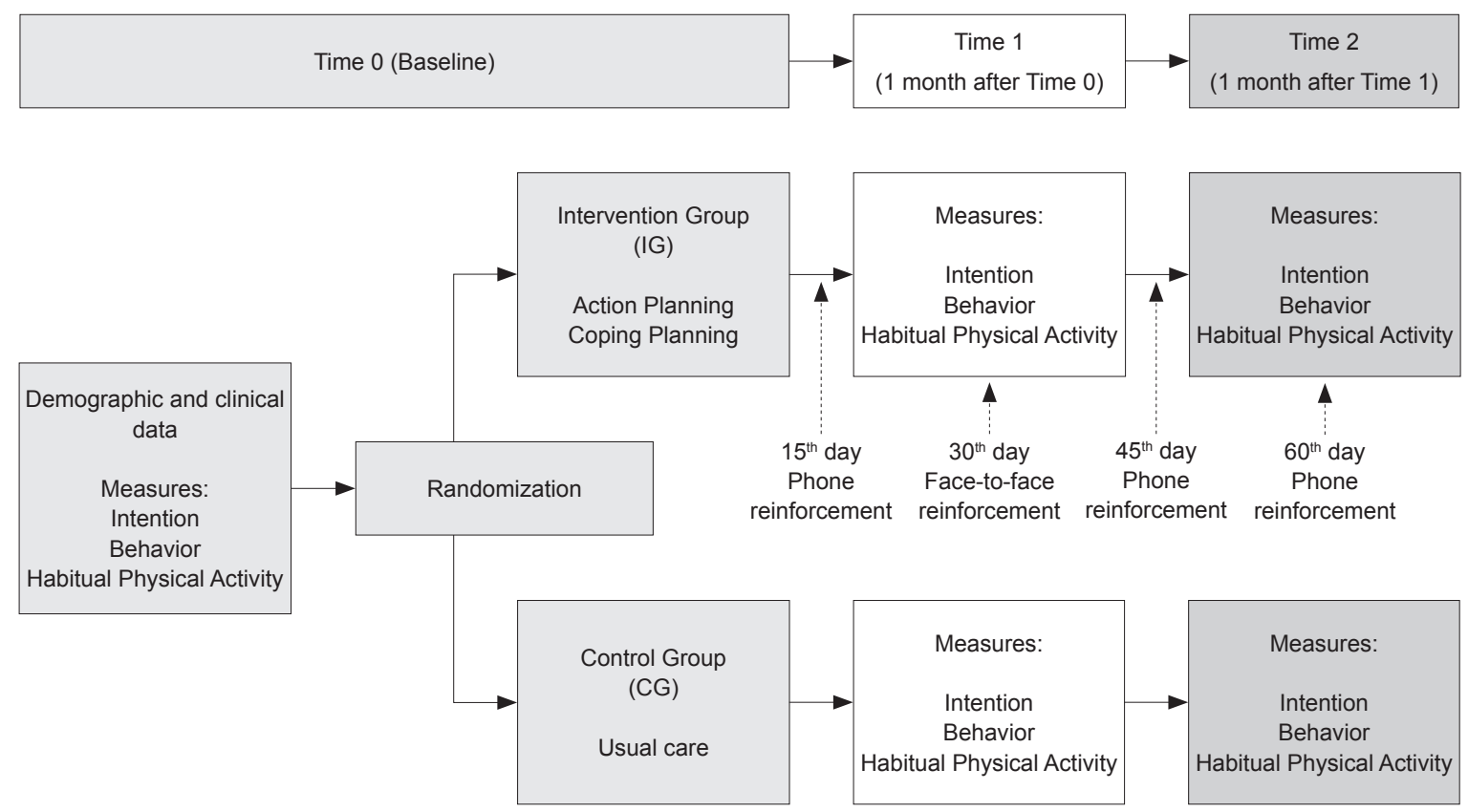

Figure 1 - Diagram for data collection procedure. 
Afterwards, the procedures of Time 0 were completed (see Figure 1). The nurse responsible for the "Moving Heart Program" took appointments to schedule posterior telephonic contacts and meetings.

In order to be included, participants should be diagnosed with $\mathrm{CHD}$ and medical recommendation to engage in regular PA. Participants were excluded if, at any time during follow-up, they presented conditions under which PA should not be implemented without supervision. Participants were discontinued if the medical recommendation of PA achieving was suspended, or if they missed the meetings, or dropped out of the Program.

At time 0, 144 patients were enrolled, but seven patients were excluded during follow-up because they missed appointments and one patient decided to withdraw from the Program. Thus, a total of 136 participants completed assessments at baseline, one and two months after. Of these, 69 subjects were randomized to IG and 67 to CG.

\section{Intervention}

The intervention design was based on previous study ${ }^{(9)}$, with some adaptations for the Brazilian culture. All the steps of the intervention were conducted by the responsible nurse in a one-to-one setting and lasted up to 40 minutes. The intervening was trained to guide the planning session in a nondirective manner. Patients were helped to write down all plans on the planning sheets (Chart 1).

\section{Step 1: Action Planning}

Participants received three identical planning sheets - one regarding PA on work environment, the second regarding $\mathrm{PA}$ in leisure-time, and another addressing everyday activities. They were asked to follow the instructions, which were read by the nurse. They should establish up to three action plans about when, where, how and with whom they intended to implement PA in the three different aspects. The planning sheet for action planning in leisure-time started with the instruction, "Please think about your leisure-time Physical Activity in the next two months. When, where, how and with whom do you plan to do it? Please write down your plans in the following table. The more precise, concrete and personally you formulate your plans, the more they can help you."

The planning sheet for action planning in work environment started with the instruction, "Please think about your Physical Activity in work environment in the next two months. When, where, how and with whom do you plan to do it? Please write down your plans in the following table. The more precise, concrete and personally you formulate your plans, the more they can help you."

The planning sheet for action planning among everyday activities started with the instruction, "Please think about your Physical Activity in everyday activities in the next two months. When, where, how and with whom do you plan to do it? Please write down your plans in the following table. The more precise, concrete and personally you formulate your plans, the more they can help you."

\section{Step 2: Coping Planning}

Additionally to the Action Planning Stage, participants established up to three coping plans about strategies to overcome anticipated barriers. The planning sheet for coping plans started with the instruction: "Which obstacles or barriers might interfere with the implementation of your exercise plans? How could you successfully cope with such problems? Please write down your plans in the following table. The more precise, concrete and personally you formulate your plans, the more they will help you." The planning sheets ended with the statement: "Memorize your plans carefully. Visualize the situations and your planned actions and make a firm commitment to act as planned."

Step 3: Phone reinforcement

In order to reinforce the plans previously established, phone calls were made in 15-day interval between the Times 1 and 2 ( $15^{\text {th }}$ and $45^{\text {th }}$ day - see Figure 1). Thus, during the phone call, participants were asked: 1. "Have you been exercising? If not, why?" 2. "Are you having any difficulty in performing your physical activity? If yes, which one(s)?" 3. "Let us recall what you had planned to perform your physical activity." After the third question, the nurse read the contents in the sheet to remind the participant of his plans. 


\begin{tabular}{|c|c|c|c|c|c|c|}
\hline \multicolumn{7}{|c|}{$\begin{array}{l}\text { THE MOVING HEART PROGRAM } \\
\text { MY GOAL: PERFORMING PHYSICAL ACTIVITY }\end{array}$} \\
\hline \multicolumn{5}{|c|}{ ACTION PLANNING } & \multicolumn{2}{|c|}{ COPING PLANNING } \\
\hline & WHEN & WHERE & HOW & $\begin{array}{l}\text { WITH } \\
\text { WHOM }\end{array}$ & BARRIER & STRATEGY \\
\hline PLAN 1 & & & & & & \\
\hline PLAN 2 & & & & & & \\
\hline PLAN 3 & & & & & & \\
\hline
\end{tabular}

Figure 2 - Planning sheet for application of intervention

\section{Instruments}

Demographic and clinical measures

At baseline (Time 0), clinical data was gathered through analysis of medical records and interview (age, gender, marital status, education level, employment status, diagnosis, cardiovascular symptoms and comorbidity, current or past smoking and drinking). The instruments used to collect this data were tested regarding the content validity ${ }^{(18)}$.

\section{Measure of Intention}

At baseline, Time 1 and Time 2, participants were interviewed and responded to the Psychosocial Determinants of Physical Activity among Coronary Heart Disease Patients Questionnaire(18). This questionnaire includes the measure of Intention and Behavior of walking. Intention was measured by six items on a Likert scale ranging from 1 (definitely not) up to 5 (definitely yes) (Cronbach's alpha in the original study was 0.95 , and in this study 0.85$)^{(18)}$.

\section{Measures of Physical activity}

Two measures were applied to assess behavior of PA at baseline, Time 1 and Time 2. One of the measures was derived from previous study(18) and was named as Selfreported Behavior measure. In this question, respondents were asked "In the last month, how many times have you walked at least 30 minutes?" This was assessed by means of a four-point scale ranging from less than 1 time per week (1) to 3 or more times per week (4).
The Habitual Physical Activity, was obtained by the Brazilian version of the Baecke Questionnaire of Habitual Physical Activity (Baecke-HPA)(19), addressing dimensions such as occupational physical activity, physical exercises in leisure, and leisure and locomotion activities. The Baecke-HPA is easy to understand and apply, and ensures qualitative and quantitative indices through 16 questions encompassing three dimensions of physical activity in the past 12 months: 1) occupational physical activities, OPA-score (8 questions); 2) physical exercises in leisure, PEL-score (4 questions); and 3) leisure and locomotion physical activities, LLA-score (4 questions). The items are scored on a five-point Likert scale, ranging from never up to always, generating each dimension, scores from 1 up to 5, with higher scores indicating higher levels of PA. The total score (HPAscore) is a summation of the three dimensional scores and the range varies from 3 (inactive) up to 15 (very active).

The measure of Self-reported Behavior measure and Baecke-HPA were used to evaluate the effectiveness of the intervention.

Follow-up - usual care (Control Group)

Control group patients $(n=67)$ received usual care, consisting of regular outpatient checkups.

\section{Ethical considerations}

The study was approved by the local Institutional Review Board. 


\section{Data analysis}

All data were analyzed using the $\mathrm{SAS}^{\circledR}$ Software (Statistical Analysis System for Windows, version 9.1.3, SAS Institute Inc, 2002-2003, Cary, NC, USA). Alpha level for statistical test significance was set a priori at $p<0.05$. Test Tukey was conducted to test differences between groups at Time 0 . Mann-Whitney Test was performed to test differences between dropouts and those at the final sample. ANOVA for repeated measures with Rank transformation was used to compare the measures of PA as the main outcome between groups over the follow-up. Cohen's Effect Size (d) was calculated to evaluate the magnitude of the effect of the Program in the Behavior.

\section{Results}

\section{Dropout, clinical and socio-demographic analysis}

The final data analyses are based upon 136 participants ( $94.4 \%$ of the initial sample). The 8 patients who dropped out did not differ from the others with respect to the variables listed in Table 1 . The patients randomized in CG and IG did not differ at baseline. In the whole sample, the majority was male (64.0\%) and with mean age of $59.2(8.0)$ years.

Table 1 - Demographic and clinical characterization of Control $(n=67)$ and Intervention $(n=69)$ Groups. Campinas, SP, Brazil, 2009

\begin{tabular}{|c|c|c|c|c|c|c|}
\hline & \multicolumn{3}{|c|}{ Control Group } & \multicolumn{3}{|c|}{ Intervention Group } \\
\hline & n (\%) & Mean $\left(\mathbf{s d}^{*}\right)$ & Median (IQR') & n (\%) & Mean $\left(\mathbf{s d}^{\star}\right)$ & Median $\left(\mathrm{IQR}^{\dagger}\right)$ \\
\hline \multicolumn{7}{|l|}{ Gender } \\
\hline Male & $43(64.2)$ & & & $44(63.8)$ & & \\
\hline Age (years) & & $61.8(8.0)$ & $61.0(12.0)$ & & $56.7(9.1)$ & $56.0(9.5)$ \\
\hline Schooling (years) & & $4.7(1.9)$ & $4.0(1.0)$ & & $4.9(2.3)$ & $4.0(1.0)$ \\
\hline \multicolumn{7}{|l|}{ Race } \\
\hline Caucasian & $54(80.6)$ & & & $58(84.1)$ & & \\
\hline \multicolumn{7}{|l|}{ Marital status } \\
\hline With companion & $52(77.6)$ & & & $45(65.2)$ & & \\
\hline \multicolumn{7}{|l|}{ Employment status } \\
\hline Active & $8(12.0)$ & & & $12(17.3)$ & & \\
\hline Inactive & $54(80.7)$ & & & $56(81.1)$ & & \\
\hline Housewife & $5(7.5)$ & & & $1(1.4)$ & & \\
\hline Family income (US\$) & & $420.9(199.9)$ & $378.5(170.4)$ & & $457.2(245.6)$ & 378.5 (198.9) \\
\hline \multicolumn{7}{|l|}{ Diagnosis } \\
\hline Infarction & $45(67.1)$ & & & $46(66.7)$ & & \\
\hline Angina & $22(32.8)$ & & & $23(33.3)$ & & \\
\hline \multicolumn{7}{|c|}{ Symptoms in the last month } \\
\hline Angina & $43(64.2)$ & & & $37(53.6)$ & & \\
\hline Dyspnea & $23(34.3)$ & & & $20(29.0)$ & & \\
\hline Palpitation & $24(35.8)$ & & & $25(36.2)$ & & \\
\hline \multicolumn{7}{|l|}{ Associated conditions } \\
\hline Hypertension & $48(71.6)$ & & & $56(81.2)$ & & \\
\hline Diabetes & $19(28.4)$ & & & $17(24.6)$ & & \\
\hline Dyslipidemia & $49(73.1)$ & & & $55(79.7)$ & & \\
\hline Body Mass Index & & $27.4(4.0)$ & $27.4(6.4)$ & & $28.4(7.0)$ & $27.0(7.0)$ \\
\hline
\end{tabular}

${ }^{*} \mathrm{sd}=$ Standard Deviation; ${ }^{+} \mathrm{IQR}=$ Interquartile Range

\section{Analysis of physical activity profile in baseline (Time 0)}

Before the intervention was applied, measures of Intention, Behavior and Habitual Physical Activity were taken. Groups were homogeneous at baseline (Table 2). 
Table 2 - Means and standard deviations for Intention, Behavior and Habitual Physical Activity in Control and Intervention Groups at Time 0

\begin{tabular}{|c|c|c|c|c|}
\hline & \multicolumn{2}{|c|}{ Control Group } & \multicolumn{2}{|c|}{ Intervention Group } \\
\hline & Mean $\left(\mathbf{s d}^{*}\right)$ & Media $\left(I^{+} R^{\dagger}\right)$ & Mean $\left(\mathbf{s d}^{*}\right)$ & Median (IQR') \\
\hline Intention & $3.9(0.7)$ & $3.8^{\ddagger}(1.0)$ & $4.0(0.6)$ & $4.0^{\ddagger}(0.8)$ \\
\hline Behavior & $2.5(1.1)$ & $2.0^{\ddagger}(2.0)$ & $2.5(1.1)$ & $3.0^{ \pm}(1.0)$ \\
\hline \multicolumn{5}{|l|}{ Baecke-Habitual PA } \\
\hline Occupational PA & $2.4(0.7)$ & $2.1(0.5)$ & $2.2(0.6)$ & $2.1(0.5)$ \\
\hline Physical Exercise in Leisure & $2.0(0.6)$ & $2.0(0.7)$ & $2.3(0.6)$ & $2.2(0.5)$ \\
\hline Leisure and Locomotion PA & $2.5(0.5)$ & $2.5^{\ddagger}(0.5)$ & $2.5(0.6)$ & $2.5^{\ddagger}(0.6)$ \\
\hline Total Habitual PA score & $6.9(1.1)$ & $6.7^{\ddagger}(1.4)$ & $7.1(1.2)$ & $6.9^{\ddagger}(1.5)$ \\
\hline
\end{tabular}

*sd = standard deviation; ‡Equal between groups - Tukey Test $(\alpha=0.05),+\mathrm{IQR}=$ Interquartile Range

\section{Effects of the Intervention}

Intention

Measures of Intention derived from the application of the Questionnaire to measure the intention to perform physical activity(18) (Table 3 ). It was observed during the follow up in both groups an increase of scores of intention. In both IG and CG, there were significant increments in all intervals (Time $0<$ Time $1<$ Time 2 ). The variance analysis between IG and CG showed statistically significant higher scores for IG during the follow up.

Table 3 - Means, sd, medians and IQR for Behavior, Intentions and Habitual Physical Activity for Control $(n=67)$ and Intervention ( $n=69)$ Groups

\begin{tabular}{|c|c|c|c|c|c|}
\hline \multirow[b]{2}{*}{ Instruments and scoring range } & \multirow[b]{2}{*}{ Groups } & \multicolumn{2}{|c|}{ Time 1} & \multicolumn{2}{|c|}{ Time 2} \\
\hline & & $\begin{array}{c}\text { Mean } \\
\left(\mathbf{s d}^{*}\right)\end{array}$ & $\begin{array}{l}\text { Median } \\
\left(\mathrm{IQR}^{\dagger}\right)\end{array}$ & $\begin{array}{c}\text { Mean } \\
\left(\mathbf{s d}^{*}\right)\end{array}$ & $\begin{array}{c}\text { Median } \\
\left(\text { IQR }^{\dagger}\right)\end{array}$ \\
\hline \multirow{2}{*}{$\begin{array}{l}\text { Intention } \\
\text { (1-5; higher score means higher Intention) }\end{array}$} & Control & $4.1(0.6)$ & $4.0(1.2)$ & $4.2(0.5)$ & $4.2(0.8)$ \\
\hline & Intervention & $4.2(0.5)$ & $4.0(0.7)$ & $4.3(0.4)$ & $4.2(0.7)$ \\
\hline \multirow{2}{*}{$\begin{array}{l}\text { Behavior } \\
\text { (1-4; higher score means higher Behavior) }\end{array}$} & Control & $2.7(0.9)$ & $2.0(2.0)$ & $2.8(0.9)$ & $3.0^{\ddagger}(2.0)$ \\
\hline & Intervention & $2.9(0.9)$ & $3.0^{\S}(2.0)$ & $3.2(0.8)$ & $3.0^{\ddagger \S}(1.0)$ \\
\hline \multirow{2}{*}{$\begin{array}{l}\text { Occupational PA } \\
\text { (1-5; higher score means higher occupational PA) }\end{array}$} & Control & $2.4(0.7)$ & $2.2(0.6)$ & $2.5(0.6)$ & $2.2(0.5)$ \\
\hline & Intervention & $2.3(0.6)$ & $2.1(0.6)$ & $2.4(0.5)$ & $2.1(0.6)$ \\
\hline \multirow{2}{*}{$\begin{array}{l}\text { Physical Exercise in Leisure } \\
\text { (1-5; higher score means higher PA in leisure time) }\end{array}$} & Control & $2.1(0.5)$ & $2.2(0.5)$ & $2.2(0.5)$ & $2.2^{\ddagger}(0.5)$ \\
\hline & Intervention & $2.5(0.5)$ & $2.5(0.5)$ & $2.6(0.4)$ & $2.5^{\ddagger}(0.5)$ \\
\hline \multirow{2}{*}{$\begin{array}{l}\text { Leisure and Locomotion PA } \\
\text { (1-5; higher score means higher leisure and } \\
\text { locomotion PA) }\end{array}$} & Control & $2.5(0.4)$ & $2.5(0.5)$ & $2.6(0.3)$ & $2.5^{\ddagger}(0.5)$ \\
\hline & Intervention & $2.7(0.5)$ & $2.7(0.6)$ & $2.7(0.4)$ & $2.7^{\ddagger}(0.5)$ \\
\hline \multirow{2}{*}{$\begin{array}{l}\text { Total Habitual PA score } \\
\text { (3-15; higher score means higher total Habitual PA) }\end{array}$} & Control & $7.1(1.0)$ & $7.0(1.1)$ & $7.2(0.9)$ & $7.0^{\S}(1.1)$ \\
\hline & Intervention & $7.5(1.0)$ & $7.2(1.2)$ & $7.7(0.8)$ & $7.5^{\S}(1.2)$ \\
\hline
\end{tabular}

*sd = standard deviation; $\neq \mathrm{p}<0.01 ; \S p<0.001-$ ANOVA; $+\mathrm{IQR}=$ Interquartile Range

\section{Behavior measures}

\section{- Self-reported Behavior measure}

The scores obtained at Time 1 and Time 2 in IG and GC are shown in Table 3. The intra-group scores showed significant increase in Intervention Group between Time 0 and Time 2 ( $p<0.001$; Wilcoxon test). Comparing the two groups, IG also had higher levels of PA than CG and this increase was statistically significant at Time 2 $(p<0.01)$. Effect size on behavior change was $d=0.66$, which constitutes a medium to large effect size ${ }^{(20)}$.

- Habitual Physical Activity

The Habitual PA scores obtained at Times 1 and 2 in both groups are shown in Table 3. There was significant increase in total HPA score $(p<0.001$; ANOVA), Physical
Exercise in Leisure-time score ( $p<0.01$; ANOVA) and Leisure and Locomotion Activities score $(p<0.01$; ANOVA) in IG individuals, in comparison to CG.

\section{Discussion}

The aim of this study was to test the "Moving Heart Program", an intervention based on the concepts of implementation intentions and aimed at promoting PA among coronary heart disease outpatients. The results showed that the intervention was effective in increasing PA levels in the Intervention Group (IG). There was an increase in Behavior and Habitual PA scores during the follow up in both groups, however, the level of PA was even higher in the IG at Time 2. 
At Time 1, the differences observed between patients at the "Moving Heart Program" and those of control group were not significant. It can be assumed that at least a period of two months is needed in order to observe changes in behavioral patterns at least regarding $\mathrm{PA}$ in this sample. The increased level of PA observed also for the Control Group, could be explained by the mere measurement effect(21) in which the simple fact of questioning the intention of the subject on a given behavior enhances his accessibility in relation to behavior, so that increases the likelihood that this behavior will be executed.

In this study, the combination of two strategies of planning, both related to the volitional strengthening phase, was effective in promoting the behavior of PA between patients with CHD. The training process of the implementation intentions starts the transformation of behavioral intention into action, which creates an effective association in memory between the individual and the desired action for its implementation. It is the link between specific action plans and opportunities that contributes to the effectiveness of implementation intentions $^{(22)}$.

Previous study conducted with 307 patients with $\mathrm{CHD}^{(23)}$, measuring the level of action and coping plans 2 and 4 months after the onset of PA, showed that Action Planning was more effective at the beginning of rehabilitation, while the individuals with higher levels of Coping Planning were more active at the end of four months, suggesting that the ideal would be the implementation of both plans, which are important in different periods of behavior maintenance.

Another study ${ }^{(9)}$ comparing the effectiveness of action planning and coping planning on the practice of PA in the rehabilitation of 211 cardiac patients also found that the combination of both strategies was more effective than the isolated use of action planning.

To our knowledge, no study using these strategies was developed with CHD outpatients or other groups with low levels of education and income, as those in this study's sample. Furthermore, there are few or virtually no studies evaluating the effectiveness of theory-based interventions to promote PA in the Brazilian population, especially among those with low income who also face the challenge of cognitive, economic and environmental limitations. One Brazilian study ${ }^{(24)}$ conducted with CHD outpatients only analyzed the action and coping plans related to the behavior of adhering to drug therapy, in order to support the application of implementation intentions to optimize adherence to drug therapy.
Thus, the results of this study indicate that the Action and Coping Planning strategies can be effective to promote the adoption and maintenance of changes in PA patterns among patients with low levels of education and income.

The study has limitations with regard to the validity of the self-report measures for physical activities. Even though the majority of papers addressing PA and cardiac risk is based on self-report methods, possible biases should be considered. Nevertheless, selfreport measures permit assessing previous behavior retrospectively and compare it with subsequent behavior or observational measures. This possibility can be considered an advantage, since it allows perceiving changes in the target behavior. Validating this study's findings in the future is advisable, by adding objective measures or longer programs.

\section{Conclusion}

This study showed that the Moving Heart Program, based on action and coping planning, was useful to enhance PA among Brazilian CHD outpatients, characterized by low education and income. Participants who established action and coping plans reported more frequent exercise and everyday PA than those who received standard care. The findings reinforce the role of the volitional processes in adopting and maintaining effective changes in healthrelated behaviors. It seems worthwhile to study individuals who fail to change behavior despite their good intentions. The presented intervention is brief and can be incorporated in hospitals and rehabilitation programs. This study's results can support educational interventions and nursing practice among patients with CHD cared for in programs of primary and secondary prevention.

\section{References}

1. Haskell WL, Lee I-M, Pate RP, Powell KE, Blair SN, Franklin BA, Macera CA, Heath GW, Thompson PD, Bauman A. Physical activity and public health: updated recommendation for adults from the American College of Sports Medicine and the American Heart Association. Circulation. 2007;116:1081-93.

2. Agarwal SK. Cardiovascular benefits of exercise. Int J Gen Med 2012;5:541-5.

3. American Heart Association. Heart Disease and Stroke Statistics-2012 Update: a report from the American Heart Association. Circulation. 2012;125:e2-e220. 
4. McEachan RRC, Lawton RJ, Jackson C, Conner M, Lunt

J. Evidence, Theory and Context: Using intervention mapping to develop a worksite physical activity intervention. BMC Public Health. 2008;8:326.

5. Godin G, Bélanger-Gravel A, Amireault S, Gallani MC, Vohl MC, Pérusse L. Effect of implementation intentions to change behaviour: moderation by intention stability. Psychol Rep. 2010;106(1):147-59.

6. Sniehotta FF, Schwarzer R, Scholz U, Schüz B. Action planning and coping planning for long-term lifestyle change: Theory and assessment. Eur J Soc Psychol. 2005;35(4):565-76.

7. Gollwitzer PM, Sheeran P, Trötschel R, Webb TL. Selfregulation of priming effects on behavior. Psychol Sci. 2011;22(7):901-7.

8. Spana TM, Rodrigues RCM, Lourenço LBA, Mendez RDR, Gallani MCBJ. Integrative review: behavioral interventions for physical activity practice. Rev. LatinoAm. Enfermagem. 2009;17(6):1057-64.

9. Sniehotta FF, Scholz U, Schwarzer R. Action plans and coping plans for physical exercise: a longitudinal intervention study in cardiac rehabilitation. Brit J Soc Psychol. 2006;11:23-37.

10. Amireault S, Godin G, Vohl MC, Pérusse L. Moderators of the intention-behaviour and perceived behavioural control-behaviour relationships for leisure-time physical activity. Int J Behav Nutr Phys Act. 2008;5:7.

11. McMillan B, Conner M, Green J, Dyson L, Renfrew $M$, Woolridge $M$. Using an extended theory of planned behaviour to inform interventions aimed at increasing breastfeeding uptake in primiparas experiencing material deprivation. Brit J Health Psychol. 2009;14(2):379-403. 12. Adriaanse MA, Gollwitzer PM, De Ridder DT, de Wit JB, Kroese FM. Breaking habits with implementation intentions: a test of underlying processes. Pers Soc Psychol Bull. 2011;37(4):502-13.

13. Luszczynska A, Tryburcy M, Schwarzer R. Improving fruit and vegetable consumption: a selfefficacy intervention compared with a combined selfefficacy and planning intervention. Health Educ Res. 2007;22(5):630-8.

14. Milne S, Orbell S, Sheeran P. Combining motivational and volitional interventions to promote exercise participation: protection motivation theory and implementation intentions. Brit J Soc Psychol. 2002; 7:163-84.

15. Conner M, Higgins AR. Long-term effects of implementation intentions on prevention of smoking uptake among adolescents: a cluster randomized controlled trial. Health Psychol. 2010;29(5):529-38.
16. Rothman AJ, Sheeran P, Wood W. Reflective and automatic processes in the initiation and maintenance of dietary change. Ann Behav Med. 2009;38(1):S4-17. 17. Thoolen BJ, De Ridder D, Bensing J, Gorter K, Rutten G. Beyond good intentions: the development and evaluation of a proactive self-management course for patients recently diagnosed with type 2 diabetes. Health Educ Res. 2008;23(1):53-61.

18. Mendez RDR, Rodrigues RCM, Cornélio ME, Gallani $M C B J$, Godin G. Development of an instrument to measure psychosocial determinants of physical activity behavior among coronary heart disease patients. Rev Esc Enferm USP. 2010;44(3):583-94.

19. Florindo AA, Latorre MRDO, Jaime PC, Tanaka T, Zerbini CAF. Methodology to evaluation the habitual physical activity in men aged 50 years or more. Rev Saúde Pública. 2004;38(2):307-14.

20. Fritz CO, Morris PE, Richler JJ. Effect size estimates: Current use, calculations, and interpretation. J Exp Psychol Gen. 2012;141(1):2-18.

21. Godin G, Sheeran P, Conner M, Delage G, Germain M, Bélanger-Gravel A, Naccache H. Which survey questions change behavior? Randomized controlled trial of mere measurement interventions. Health Psychol. 2010;29(6):636-44.

22. De Vet E, Oenema A, Sheeran P, Brug J. Should implementation intentions interventions be implemented in obesity prevention: the impact of if-then plans on daily physical activity in Dutch adults. Int J Behav Nutr Phys Activity. 2009;6:11.

23. Sniehotta FF, Scholz U, Schwarzer R. Bridging the intention-behavior gap: planning, self-efficacy, and action control in the adoption and maintenance of physical exercise. Psychol Health. 2005;20(2):143-60.

24. Lourenço LBA, Rodrigues RCM, Spana TM, Cornélio $M E$, Gallani MCBJ. Action and coping plans related to the behavior of adherence to drug therapy among coronary heart disease outpatients. Rev. Latino-Am. Enfermagem. 2012; In press.
Received: Aug. $1^{\text {st }} 2012$ Accepted: Oct. 23 2012 